\title{
William Faulkner's The Sound and the Fury: The Status of the Popular in Modernism
}

\author{
Luis M. García Mainar \\ Universidad de Zaragoza
}

\begin{abstract}
This paper is an attempt to assess the attitude of a modernist work towards popular culture and the social changes that transformed the United States during the twenties. Its main contention is that modernism's emphasis on epistemology has tended to obscure the conservative stance of many of its creations, apparent in their reaction against the new reconsideration of class and gender brought about by industrialisation and urbanisation. Following a combination of textual and cultural analysis, the paper scrutinises the ways in which Faulkner's The Sound and the Fury negotiates the presence of those social changes.
\end{abstract}

William Faulkner's The Sound and the Fury was first published in 1929, right at the end of a decade that had transformed the United States more visibly and intensely than any other period of modern America. This change involved many different spheres of public life, but the effects of the new times were perhaps most strongly felt in the realm of private personal experience, where sexual behaviour and attitudes become illustrative examples. As John D'Emilio and Estelle B. Freedman state, in the years from 1880 to 1930 the gradual industrialisation and economic transformation the United States underwent resulted in strong tensions within the middle-class family, which lost part of its hegemonic status. These tensions were produced by the easy access of men to a world of commercialised sex, while women were still perceived through notions of purity. At the same time, the movement of women outside the domestic sphere offered new opportunities for nonprocreative, nonmarital forms of sexual behaviour. In the middle classes, some women rejected men completely, while young working-class women engaged in new 
forms of heterosexual relationships that accepted premarital sexual intercourse. The working class youth also began to discover a world of commercialised amusements that shocked the middle-classes in its connections with a sexuality outside any established norm or control. The reaction was immediate, as white middle-class reformers attacked what for them was working-class immorality. Sexuality therefore became one way of controlling this danger. A gradual loss of nineteenth-century norms of continence and selfcontrol led to new codes of behaviour that relied on indulgence in sexual matters (202-21).

In the 1920s, Americans had entered a new sexual era. The erotic was valued positively, the youth were growing more and more independent, sex was associated with commercialised entertainment while it also became a means of self-expression. The erotic became more and more visible in cultural forms, and women's pursuit of sexual pleasure started to be accepted as natural. This change in sexual mores was accompanied by the gradual appearance of a consumer economy, which was going to present the purchase of products as a pleasurable activity that allowed self-expression, an indulgent attitude which was quickly associated with sexual conduct. Throughout the decade, the country was approximating a notion of the erotic that has later come to be defined as sexual liberalism. It was an attitude that stopped associating sexual activity with procreation, placed pleasure as a value in itself, and proposed sexual satisfaction as an essential ingredient of happiness and successful marriage; it also allowed some space for youths to experiment with sex as preparation for their adult life. The image of women changed as the flapper appeared: she embodied the new woman, independent and seductive, associated with smoking and bootleg, who looked for freedom through sexual availability (Fear, McNeil 250). This new sexual code produced a new attitude to marriage too, and the concept of "companionate marriage" appeared A more egalitarian relationship, it proposed emotional compatibility, rather than the fulfilment of gender-defined roles, as the basis of a successful marriage. However, this was a kind of relationship that was only contemplated by white middle-class couples. Working-class couples continued to engage in relationships where gender differences produced unequal perspectives on marriage. Different access to sexual information and sexual experience before marriage, together with the absence of effective contraceptive practice, led working class marriages to patterns of behaviour very close to those of previous decades. Sexual liberalism was therefore only the aspiration of white middle-class couples, whose affluence allowed an intense focus on the privatised couple of the companionate ideal. Sex was still felt as a mark of identity that separated married couples along lines of class difference (D'Emilio, Freedman 222-74).

The social division between the affluent and the poor and the immigrant was present throughout the 20s. Sacco and Vanzetti were executed in 1927, after being convicted for a robbery in 1921 on what many considered insufficient grounds. They were condemned to death after a group of Boston white Anglo-Saxon Protestants prevented a retrial of the case. The fact that the two convicts were Italian immigrants and anarchists was felt by public opinion as a determinant factor for the angry reaction of the hegemonic wealthy white community, afraid of the increase of immigration and the working-class. Prohibition also foregrounded the conflicts between the different components of US American society, as a traditional Protestant America tried to control a rebellious and impoverished immigrant minority. Another great divide also appeared between the inhabitants of cities 
and rural America. From 1920 to 1930 the figures of Americans living in cities rose from $50 \%$ to $69 \%$, as US America gradually became an urban landscape. The city became the main economic force, as it expanded and produced middle-class suburbs where consumerism became the norm. Advertising developed in order to market the great number of goods this affluent society manufactured. Workers enjoyed the benefits of expanding capitalism, until the Crash of 1929 brought them and their employers back to a hard reality. The mass culture of radio, film and popular magazines produced a homogeneous ideal behaviour that all classes aspired to share; it therefore generated a new kind of conformity based on middle-class consumer values. This new ideal of the masses combined emphasis on consumerism with emphasis on personal freedom: buying a share of the goods in the market was an expression of individual freedom which at the same time allowed one into the wished-for world of middle-class values. The passivity inherent to this allegedly active conduct seemed to remain concealed by the allure of the market (Fear, McNeil 233-61).

This brief and sketchy view of US America in the 20s contrasts with the impression the reader of The Sound and the Fury gets about that same reality. The novel's concentration on the internal life of the characters, on their very personal filtering of external information, usually manages to draw the reader into the very specific world the characters create for themselves. This is so to the extent that references to the historical and social changes that were taking place at the time seem somewhat alien to the private experiences the novel has chosen as its centre. However, if one stops and looks into the events and characters from a more external point of view, if one manages to detach oneself from the internal perspective the novel fosters, one can very easily establish obvious connections between the novel and the context in which it was produced. The study of modernism has traditionally lacked analytic approaches that did not. focus almost exclusively on its very particular formal devices. Recent studies have attempted new considerations of modernism from more cultural and gender based points of view, which usually reveal the importance of the popular and of gender issues. Inattention to these ingredients has traditionally shaped a view of modernism as a purely aesthetic movement. Works such as Scott's (1990), DeKoven's (1991) and Felski's (1995) have contributed to a new assessment of modernism that, in its consideration of low cultural forms and marginal ways of writing, already includes many of the features usually attributed to postmodernism. ${ }^{1}$

This essay is an attempt to think about this influential novel of the 20 s from a point of departure based on the discrepancy between the novel's aspirations as mirror of a psychological internal world, and the connections with modernism this involves, and the novel's place in the social and literary context that saw its appearance. The aim will be to place this prototypical modernist novel in a historical space where its modernist claims can be viewed from a new point of view, from the perspective of the implicit denial of certain literary and social ingredients on which modernism erected its magnificent edifice of literary eminence. The essay will attempt to probe into the very personal, individual quest for knowledge offered by modernism in order to bring to the open the concealed suppression of the popular ingredient of literature. In the process, the association of the popular with femininity and $20 s^{\prime}$ female sexuality will be revealed, as the novel creates 
itself by denying the emergent role of new literary modes from mass culture and of new sexual mores illustrated by the new woman.

In their influential and oft-quoted reflection about modernism, Malcolm Bradbury and James McFarlane have described it as a high aesthetic self-consciousness, associated with non-representationalism, with a thrust away from realism and towards style, technique, towards form in one word, as tocls to penetrate life deeper. The reality of modern times becomes discontinous, producing a crisis in traditional ways of understanding. This is somewhat prevented through the elaboration of an art that includes discontinuity but where this broken reality is located within an aesthetic system that reorders it. The artist can therefore transcend history and reality by his/her technique. This new paramount role of artistic form produced a movement towards sophistication, mannerism and technical display which was accompanied by introversion and internal self-scepticism. Modernism is presented by Bradbury and McFarlane as the artistic tendency that best responded to the chaos set loose by the modern era. The world of epistemological relativity created by Eisentein's theories, by the experience of Worl War I, and by the influence of Marx, Freud and Darwin, led the modernist writer to draw scenarios of instability and doubt. Literature therefore attempted to destabilise traditional views of homogeneous and communal reality, together with conventional notions of causality. The idea of the wholeness of individual character was undermined, while public notions of language were discredited as propaganda and all realities became subjective fictions (19-29)

It is in this modernist vital and aesthetic context that The Sound and the Fury is first to be located. The novel has been analysed as a complex example of the perspectivism offered by modernism as a problematisation of the subject's epistemological quest. The four sections of the novel are told by different narrators, the first three by characternarrators Benjy, Quentin and Jason, the last section being narrated by a heterodiegetic agent, a narrator who is not a character in the story. The first three narrators introduce their very personal views on the events that have shaped the Compson family, who represent the gradual decay of the American South at the beginning of the twentieth century. The different perspectives these three narrators and focalisers offer on those events set the novel as partly a reflection on the lack of a core of inmutable reality to be shared, the lack of a keystone to an understanding of reality. The last section's use of a heterodiegetic narrator and an external focaliser approximates the novel to the realist text. But the implicit attack on a stable notion of reality also seems to affect this section. It unmasks it as merely another attempt to offer a perspective on the events, one that follows the codes of realist literature, and that consequently reveals such realist literature as a subjective view presented through an allegedly objective form. Not even the mythic resonance the text may produce seems to provide a hopeful answer to the reader's search. The pattern of temporal references to Holy Saturday, Corpus Christi, Holy Friday and Easter Sunday, together with the indirect links the novel makes between Benji, Quentin, Jason and the figure of Jesus Christ seem part of a mythic discourse that would result in resurrection after death. However, Miss Quentin's escape becomes a parodic finale to what might have been hopeful: her room is found empty, like a new sepulchre which did not hold a new Christ figure, but a wild girl who has escaped with a lecherous man (Collado 105-13). 
This analysis of the novel manages to prove the connections between the text and the modernist concerns of the time. However, it neglects the study of the social and cultural background of the years in which the text was written. The novel is very emphatic on the role played by Caddy, the sister to the three narrators, who becomes the site where their innermost feelings are distilled and hoarded. Caddy is the object of the affection of mentally retarded Benjy, the symbol for the lost innocent South in melancholy Quentin's conscience, and the representative of missed opportunities for bitter Jason. The three brothers seem to make their lives revolve around this female figure whose sexuality will destabilise the world as they know it. Caddy's craving for romance and contact with young men, her loss of virginity, her lovers, her pregnancy and her marriage to Herbert Head change the world for Benjy and, especially, for Quentin, who still remain very much attached to her. The broken marriage, whose cause seems to be Head's realisation that he is not the father of the child, leads Mrs Compson to forbid anybody to mention Caddy's name. Caddy's child, a daughter named Quentin in memory of her brother, is nevertheless accepted, she will live with the Compsons and will repeat the same sexually notorious behaviour of her mother, until she decides to run away with a stranger and escape from Jason's reach. The story covers the events in the Compson family from 1898 to 1928, a time in which the social texture of America was rapidly changing along the lines sketched above. The presentation of sexuality in the novel becomes relevant from this point of view, as an exploration of the way this prototypically modernist text has reworked a major change taking place at the turn of the century: the appearance of new sexual conducts shaped by class origins.

Caddy's behaviour in sexual matters, her loss of virginity with a stranger, and her casual lovers, coincide with the new emerging prototype of female. She resembles the youth's approach to sexuality in the playful manner she adopts regarding sex, and in the acceptance of premarital intercourse; and she resembles the attitude of working-class couples in her unwanted pregnancy and the absence of contraceptive practice. She seems to represent both a certain sexual liberation and a class ingredient that allies her with a low economic status. These liberation and working-class attitudes seem to become the cause of Quentin's and Jason's anxieties, which are nevertheless concealed under a moralistic discourse. They reject their sister's behaviour as unacceptable from a moral stance, while in fact they are deeply affected by the female freedom she represents and by the workingclass connotations of an unwanted pregnancy and an arranged marriage. Through Caddy's behaviour, they are reminded of the loss of economic power the Compsons have had to face, of the sale of the pasture to pay for Quentin's education, and of Jason's modest job in a hardware store. And they are also reminded of the freedom they cannot enjoy, Quentin being tied by his college education (and a mental world which ultimately leads him to suicide) and Jason by a drab existence. The pleasure of sex Caddy has discovered is regarded as excessive by her brothers. It is a threat to the established society of the old South Quentin is so fond of, and to the new social organisation represented by Jason, who cannot find in her the proper support to thrive in the emerging money-orientated society: her husband was to have given Jason a job at a bank but the break-up prevented it. At first she seems to embody two kinds of pleasure, that of enjoying herself and satisfying her desire, which is regarded as dangerous and disruptive, and the pleasure that inscribes the 
individual into the social texture through the creation of a family. This latter kind of pleasure disappears with her husband, preventing Jason's benefit from it, Caddy therefore becoming the excess of self-centred pleasure.

This account of Caddy, and of her position in the text, resembles the position and workings of what John Fiske has called the popular text. For him the popular text is mainly defined by the existence of two apparently contradictory kinds of pleasure which he identifies with Barthes' concepts of jouissance and plaisir. The former is a bodily pleasure that is experienced at the moment culture is broken down and replaced by nature. It involves loss of the self, which results in the evasion of ideology, of the socially created meanings that bind the individual. The latter is produced by that same social organisation, and its roots are in the dominant ideology. It is interested in social identity and recognition. Jouissance produces the pleasures of avoiding the social structure and order, plaisir produces the pleasures of relating to this social order. Plaisir is not necessarily a conformist pleasure, it becomes a pleasure because it is created by the people who experience it, and its form will vary from the reactionary to the subversive depending on the position of the individual in society (49-54). Fiske is also useful at this point in his proposal to link pleasure and antagonism. For him the movements of culture are best explained through metaphors of struggle or antagonism between social groups, different ideologies or kinds of power, between discipline and disorder. These confrontations of social forces are mainly motivated by pleasure, a pleasure he defines as "the pleasure of producing one's own meanings of social experience and the pleasure of avoiding the social discipline of the power-bloc" (47). The popular text is the site of these struggles, the arena where people can produce their own meanings and attempt to escape from those meanings imposed on them. Caddy occupies such a position in Faulkner's The Sound and the Fury. She is to be read as representative of the popular because she stands for an antagonism which is clearly motivated by pleasure, by her desire to experience contact with men. Her loss of virginity and her lovers are attempts to avoid the social discipline of her family and her time. At the same time, her pregnancy is turned into a mechanism of integration into society through marriage away from the family. She is the only Compson who will have offspring. In fact, the mixture of evasion from social rule and integration is present in her from her childhood. Grandma's death episode reveals a rebellious Caddy who disobeys the orders of the adults and climbs up the pear tree to look into the house and find out what all the fuss is about. She draws her brothers and the servants' children with her, at the same time cementing a kind of camaraderie between them that will mark their relationship with her from then on. Caddy, on top of the tree and in her future life, becomes a text to be read by the other characters, and an ambiguous text, like the popular text. She becomes a symbol for the people and their cultural products, it is then not chance that Miss Quentin, Caddy's daughter and partly her alter ego, runs away with a man from the travelling show.

Caddy's complex web of meanings includes a view of feminity that has come to be identified with modernism. Quentin regards his sister as the point of connection between the family and nature, she stands for affection but also for a sexual allure he has felt and then repressed. Quentin's contact with a young girl in his childhood is presented as a displacement of the desire he feels for his sister, something that becomes clear when he later rubs mud all over her. Caddy's presence at school allowed Quentin to show his manly 
Southern code by fighting anyone who offended her. For him she becomes almost a mythic figure related to the past he would like to live in, and unaffected by the social changes that have produced the decay of the family. She stands for the comfortable private realm of the family against the dangers of public life, which he identifies with male rule. For Quentin, men inhabit a harder world where they are subject to the dangers of modern life, to selfdivision and crisis, which in his case will develop into mental disorder. This quasymythical view of women is also illustrated by Dilsey, a character most clearly associated with the natural world, the passing of seasons, and the stoicism that seems necessary to endure life. Women are presented, from the point of view represented by Quentin, as isolated islands of peace and stability, who establish precious bonds with the past and nature, bonds the novel will try to privilege in the fourth section as one possibility of escape from the relativist position it has created for the reader. Caddy will grow up to become unacceptable by Quentin's idealised mental world, she will transform into the seed of moral degeneration, shattering the blissful fantasy of purity and courtesy his brother had cherished so much. After Caddy disappears from the horizon of the family's hopes, Quentin can do nothing but commit suicide.

Caddy also emerges in the novel as the dangerous woman in her capacity to have access to money. She will send money to the Compsons for the support of her daughter Quentin, money Jason steals by cashing the cheques Mrs Compson's pride has decided to reject. Caddy becomes a woman who can use money in order to persuade Jason to let her see her daughter. She seems to enjoy, in Jason's account of the story, a better economic position than her family do, and this economic power is resented by her brother, who cheats her by taking her money and not allowing her to visit Miss Quentin. Caddy is also dangerous for the feminised Quentin because she represents the earthy side of human nature. Quentin is too weak to accept her sexualised sister, he is the sophisticated male who enjoys artifice and aesthetics, who prefers symbols to realities. At this point, and from the perspective of Quentin's worldview, she is also regarded as part of a lower class, as the disagreeable side of a mediocre modern life. She is vulgar, Quentin is refined. This lower status is illustrated through the development of her story. She is the young girl who is seduced and then abandoned, who has to marry in order to preserve her honour, but whose marriage does not last. At the close of the novel she remains a solitary woman, whose return home is impossible after the loss of her honour. This is the prototypical story of a melodramatic character, who introduces the underrated codes of melodrama into a highly stylised modernist text.

This account of Caddy's representation lays bare an obvious attempt on the part of the text to use gender patterns in hidden ways in order to reinforce the relationships between the different characters. These patterns of gender are not arbitrary, but tend to consistently qualify the female prototype embodied by Caddy as different and dangerous in her difference. The views of nonalienated, nonfragmented female identity are recurrent motifs in modernist works. The mythic plenitude and nostalgia with which Caddy is invested by Quentin indirectly characterise her as outside the process of social change, as contained within the private realm of the family, alien to development and progress, which are associated with the public male world. When Caddy actually develops, grows up and discovers sexuality, she becomes the dangerous woman ready to satisfy her desire, not 
only her bodily desire but the consumerist one too, she will invest money in her daughter and in her visits to her. She comes to stand for modern consumerism, associated with the popular and the lower classes. She also becomes a sexual threat to the aestheticised, refined male Quentin represents, to the dandy who inhabits an ivory tower of symbols against the harsh reality of the mediocrity of modern life. Caddy, and woman in general, becomes the symbol of vulgarity, of the ordinary quality of common people. This popular ingredient is also indirectly introduced in the very stereotypical narrative that creates Caddy, a melodramatic ingredient which sits uncomfortably with the rest of the text. These representations of femininity have been carefully studied by Rita Felski in her account of modernity. She reaches the conclusion that the texts of modernity tend to place this misogynist core as basis of their aesthetic pursuits $(35-145,207-12)$.

I would now like to approach the figure of Caddy from a slightly different perspective, although one based on the ideas previously outlined. As has been argued above, Caddy works as a commodity, as a text, to be consumed in the first era of consumerism and advertising in America, the 20s. She is in fact exchanged in the way a commodity is in capitalist societies. Her brothers share her as a symbol of their desires and frustrations, of their yearning for affection or the lost past. Her meaning seems to depend on the attitudes of her brothers, like the value of a commodity depends on the relationships between the components of the market. Slavoj Zizek's comments on Marxist theory are useful at this point. For Marx, commodity fetishism is a set of social relations between men that assume, in their eyes, the form of a relation between things. The value of a commodity is measured by the money it may produce. For Zizek, the essential feature of commodity fetishism is the misrecognition of the relation between the network of exchange and one of its elements, money; "what is really a structural effect, an effect of the network of relations between elements, appears as an immediate property of one of the elements, as if this property also belongs to it outside its relation with other elements." (24). Money is therefore invested with an aura of value which is in fact only the result of its being within the structure of exchange of commodities. The whole system, however, works because we decide to ignore that money has no value in itself: we know it is only a relational measure but we behave as if it had value in itself and we therefore try to accumulate it.

For Marx, the difference between pre-capitalist and capitalist societies is that in the former commodity fetishism is not yet developed, and the relationships between men are still apparent in relations of domination and servitude. In The Sound and the Fury we seem to be facing a capitalist system which still retains certain ingredients of a pre-capitalist society. Caddy is treated as a symbol whose meaning is created through her relationship with the different elements (brothers) in the family, and this seems a mechanism that fits the capitalist system of exchange. However, she is at the same time also entangled in a web of servitude, since her development as a character is going to lead her to submit to Jason's desires, to act as a servant completely dominated by her brother. She seems a point in the text where the pre-capitalist relations between men burst into the capitalist relations between things, a point that threatens to destroy the newly created system of commodity exchange Jason represents at the end of the novel.

Zizek posits his notion of the symptom as a dangerous element within social systems because it stands for the most essential basis on which the social edifice is erected, a basis 
which has to be concealed because it is at the same time rejectable. For him the symptom is to be found in the passage from feudalism to capitalism. The establishment of bourgeois societies meant the repression of relations of servitude; however, these repressed forces threaten to emerge and appear in capitalist societies, showing the persistence of domination and servitude, and subverting the ideological appearance of equality and freedom on which capitalism stands (26). Caddy's presence is therefore perceived as necessary to create the system of exchange but at the same time as an element that threatens to take the characters back to a pre-capitalist system where domination predominates over equality. She seems to enter the realm of commodity fetishism not as an individual, but as a thing, a commodity to be exchanged. Here her status as female character places her both in the pre-capitalist and the capitalist systems, both as servant and commodity, revealing the relevance of women for the maintenance of the capitalist society of the Compsons, and by implication for the establishment of patriarchal capitalism. $^{2}$

Now, this structure in which the value of a commodity is expressed through reference to another commodity resembles the Lacanian theory of the mirror stage, in which the ego can only arrive at its self-identity by being reflected in another person, identity and alienation being intimately related (Zizek 24). The formation of the brothers' identity seems to depend on their being reflected in their sister Caddy, who becomes both site of self-identity and representative of the difference they are not willing to accept. She must therefore be present and at the same time absent in order to fulfil her function as defining force for the family, while her relevant position in that system is to be repressed, since she might reintroduce the element of difference against which the family, her brothers, have defined themselves. She is also the symptom that is necessary to constitute the family but which has to be forgotten in order to secure its welfare, similarly to the function of the relations between men in pre-capitalist societies mentioned above, and which are also to be repressed. Zizek also calls this threatening ingredient the real, which stands behind the transaction of commodities but is repressed and turned into the fantasy that supports the exchange, the real that stands behind the constitution of the self and whose repression produces the fantasy of unity of the individual. In the case of Caddy, the real behind the symbol remains: she is Caddy, a human being whose excessive meanings are constantly the object of her family's attempts to reduce her and constrain her to a single meaning. But she resists, and returns in the shape of her daughter Quentin, who is also sexually promiscuous and who reworks Mr. Quentin's passive role in the novel as one of opposition to Jason.

Caddy therefore appears as the absent element that sustains the symbolic world of the Compsons, most explicitly through the money she gives to Jason for Miss Quentin. She supports that world by at the same time feeding Miss Quentin inside the family, the seed of disruption and rebellion within Jason's money-oriented and tense world. Miss Quentin is the excess, the symptom that stands for Caddy and becomes necessary for Jason's world to exist: she feeds his rage, which is in fact a rage against the economic decay of his family and the entrance into the new bourgeois world of exchange of commodities where he has not much to exchange. So, Miss Quentin appears now as creator of meaning and symptom that stands for the absent support of ideology, one that needs to be denied for its function 
to be performed. From this point of view, her disappearance, Christ-like fashion, is not only a parody of the Christian myth, but also the basis of new social relations that rely on the exchange of commodities. This exchange is created along very specific gender lines, those of the female body, which becomes the main commodity to be exchanged in a decade when advertising gradually brought sexuality to the open. It is this use of woman that the novel has repressed while turning it into the kernel of the real which cannot be reduced to the symbolic world; it has become the ingredient of the real that exceeds the world of the Compsons, and at the same time constitutes it.

Zizek links this role of the symptom, of the real, to the function of ideology. For him ideology is not a fantasy that prevents the subject from knowing social reality, a false consciousness, as Althusserian Marxism stated. On the contrary, the function of ideology is to offer social reality to the subject as a fantasy that works as an escape from some traumatic kernel of the real. So, the whole social reality is a fantasy meant to structure a coherent world. Antagonism, confrontation, is usually the traumatic kernel, a traumatic social division which cannot be symbolised (45). The world of the Compsons appears as an emerging capitalist society that attempts to escape from the relations of servitude on which the Old South had been based, and from a conception of women as dangerous aliens. Both the topics of the Old South and the glamour and value attached to femininity in that lost aristocratic world appear as a result of the attempt to fetishise a difference which was felt to be threatening and on which the whole system of economic relations was based. However, the presence of Caddy and Miss Quentin still represents the persistence of a social division which the new social forms of the 20th century cannot symbolise: the conflict between an alleged equality and the actual social practices that tend to place women as commodities and defining terms for the identity of men, two functions that imply the use of women and the disavowal of that use, the repression of that relational activity performed by women and on which patriarchy stands. The new social reality of the emerging capitalist $20 \mathrm{~s}$ is the fantasy that results from the repression of this real kernel, of this traumatic underlying system of relations. This kernel of the real is the keystone of that new social system, a kernel which cannot be symbolised, for which we can only find a signifier without a signified. This signifier is a pure signifier because the real offers no support for its symbolisation: the signifier that refers to that real kernel is a pure signifier, lacking a signified (Zizek 95-97). And this is the position occupied by Caddy, a pure relational element, purely a signifier, her signified actually depending on the positions of the members of her family with respect to her.

If we return now to our previous considerations on the novel's use of popular culture, and we view them from the new perspective of the previous paragraphs, we will be able to refine our reading of Caddy as a popular culture text. From this perspective, she also becomes a symptom of the novel's pretensions to become high culture. In fact, the novel's use of Caddy as the absent element that always returns and that resists symbolisation confers on her (as popular culture text) the status of the real, at the same time as it reveals the novel's attempt to hide it. The novel's claims to be considered part of the complex side of modernism, of the formally deviant text, are in fact based on the repression of the popular-text element in it. Because in fact the readers, no matter how perspectivism is upheld here, are demanded to follow the course set by the different narrators, so that their 
appreciation of reality is coded, symbolised by the text, with the help of those clarifying sources that the different sections become for the temporally preceding ones. This inscription in the symbolic renders the novel's perspectivism a controlled one, which does not really want to completely bar the readers' access to the meaning of the text. In contrast, Caddy, as an element that resists symbolisation, does provide a potential point of breakdown of symbolisation of the text coherent with modernist aesthetics. This potential breakdown is associated with a multiplicity of perspectives on her that are not controlled by the different narrators. She is a much more mobile and flexible concept, to be negotiated by characters-readers, in the way popular culture is. This more genuine disruptive element is however relegated to a corner of the text, at the same time becoming the symbol of the textual tendency that the novel really wants to reflect, of the instability of meaning. In order to allow the four-narrator perspectivism to become convincing, this element must be absent from the text, from the world of the Compsons. It therefore makes the novel possible by its very absence. Its appearance would make the process of interpretation, carried about her by the rest of the characters, impossible, and would therefore do away with the element that brings the four parts together. Her absence is necessary for the coherence of the novel's modernist attempt. Her status as popular culture text reveals the novel's attempt to ostracise what in fact has created the novel: its popular nature. This is typical of the modernist tendency to attract attention to its formally innovative techniques as support of their subversive quality, while presenting itself as different from the popular text. This move is illustrated in the novel, at the same time revealing its ultimate reliance on the popular, perhaps because modernism was in fact a result of changes taking place at the turn of the century among the people: industrialisation, consumerist anxiety, advertising, were all possible in as much as they engaged the people. Faulkner's novel addresses this issue but in covert ways that become meaningful because of their covertness.

Caddy's role as the real kernel of the popular is also amenable to further readings. According to Lacan, the real is that which resists symbolisation, the traumatic point which is always missed but always returns, no matter how much we try to neutralise it, to integrate it into the symbolic order. It is the symptom which is conceived as such a real kernel of enjoyment (69). For Zizek, this part of the real that always returns is an element of enjoyment. This joyful side which persists as a surplus is close to the notion of jouissance used by Fiske as defining feature of the popular text. Caddy is also a popular text in that she embodies enjoyment, an excessive joy that goes beyond the limits of the symbolic represented by her family, which fits into the category of the kernel of the real that Zizek will call the symptom. What is characteristic of the symptom is that it stands for an irreducible excess that is at the same time absent and constitutes our symbolic, an excess associated with joy : joy constitutes our symbolic. It is only Faulkner's decision to place himself and his book on the side of elitist literature that relegates such joy--that is Caddy, the popular text--to a dark corner of the novel.

The text therefore appears as an elitist product, so constructed in its use of selfconscious narrative techniques, which has built its elitist claims on an implicit repression and displacement of the popular, which is associated with woman and the working class. This move reveals the gender- and class-biased politics of a part of modernism, which does 
not so much attempt to explain the complexity of modern life, as modernism has been claimed to do, as, on the contrary, to control it and stop its change. This potential change seems to promise new gender and class scenarios the novel, and implicitly a part of modernism, refuses to accept. The originality of the novel is shown in its illustration of the subjectivity of knowledge, and of the impossibility of objective knowledge, but it conceals a very stark separation between male and female characters, which are at the same time also differentiated along class lines. Such a new self-consciousness of modernism stops at the consideration of knowledge, and does not go into other ideological patterns also involved by representation.

At the same time, The Sound and the Fury proves Zizek's idea that ideological systems already incorporate in themselves a certain self-consciousness about their biased nature, and that this awareness does not, nevertheless, lead to a destruction of the ideological construct, but, on the contrary, it becomes one of its bases. This is so because ideology cannot be subverted from the level of representations, to which this self-consciousness refers. Ideology emerges from the unconscious, structuring a fantasy of the real world that allows us to escape from some irreducible kernel of the real we cannot bear. This irreducible kernel is present in the process of signification too, in the form of the surplus meaning associated to a signifier, a meaning which cannot be symbolised but which becomes the basis of the signifier. Caddy's femininity and low class behaviour stand for this surplus meaning which her family and the novel cannot assimilate. The proof of this incapacity to assimilate her on the part of the novel is the attempt to construct her as a nostalgic figure, a consumerist female, which links her to Dilsey's mythic status-in fact one way of subjecting femininity by presenting it as natural and therefore outside the public arena-or to the threats of modern life-she is also stigmatised as consumer, as the voracious female whose desire threatens patriarchal society.

As Felski argues, modernism presented itself as an experimental art intent on subverting established notions of world perception identified with the bourgeois/patriarchal order. However, it has contributed to the marginalisation of women and of certain kinds of texts, such as realist or melodramatic ones, which were also created in the same period and were associated with female writers or readers (28). The Sound and the Fury exemplifies this modernist credo of subversion, which at the same time marginalises both women and the popular and working class connotations associated with them. The unconscious structures that shape the fantasy that sustains the symbolic world of the novel are therefore revealed to include a misogynist component and a class prejudice that nevertheless emerges in a hard kernel of the real the text cannot control: Caddy.

\section{Notes}

1. For a good account of the relevance of gender and cultural issues in modernism, and of the postmodern quality already present in it, see Juan A. Suarez's recent "Modernism and Gender Trouble". 
2. Eve Kosofsky Sedwick makes a similar point in her well-known book on homosocial desire. She posits male homosocial desire, relationships between men which may range from friendship to homosexuality, as the basis of patriarchal societies, where women's role is simply to cement the bonds between men-Patriarchal heterosexuality, and by implication patriarchal society, relies on the traffic of women between men (1-20).

\section{Works Cited}

Bradbury, Malcolm and James McFarlane. "The Name and Nature of Modernism." Modernism: A Guide to European Literature 1890-1930. Eds. M. Bradbury and J. McFarlane. Harmondsworth: Penguin, 1991 (1976). 19-55.

Collado Rodríguez, Francisco. "Narratology, Myth and Dissolution in William Faulkner's The Sound and the Fury." Anuario de Estudios Filológicos, XIV. (1991): 105-13.

DeKoven, Marianne. Rich and Strange: Gender, History, Modernism. Princeton: Princeton UP, 1991.

D'Emilio, John and Estelle B. Freedman. Intimate Matters: A History of Sexuality in America. New York: Harper and Row, 1988.

Fear, Jacqueline and Helen McNeil. "The Twenties." Introduction to American Studies. Eds. M. Bradbury and H. Temperley. London, New York: Longman, 1994 (1981). 233-61.

Felski, Rita.The Gender of Modernity. Cambridge: Harvard UP, 1995.

Fiske, John. Understanding Popular Culture. London, New York: Routledge, 1996(1989).

Scott, Bonnie Kime ed. The Gender of Modernism: A Critical Anthology. Bloomington: Indiana UP, 1990.

Sedgwick, Eve Kosofsky. Between Men: English Literature and Male Homosocial Desire. New York: Columbia UP, 1985.

Suárez, Juan Antonio. "Modernism and Gender Trouble." Cuadernos de Filología Inglesa 6/1 (1997): 9-31.

Zizek, Slavoj. The Sublime Object of Ideology. London, New York: Verso, 1994 (1989). 